\title{
RELATIONSHIPS BETWEEN SPORULATION, ENTERO- TOXIN PRODUCTION, AND INCLUSION BODY FORMATION IN CLOSTRIDIUM PERFRINGENS NCTC 8798
}

\author{
KENJI TAKUMI,* AYA TAKEOKA, TETSURO KOGA, \\ AND YAETA ENDO ${ }^{1}$ \\ Department of Food Microbiology, School of Medicine, University of Tokushima, \\ Tokushima 770, Japan \\ ${ }^{1}$ Department of Biochemistry, Yamanashi Medical College, \\ Yamanashi 409-38, Japan
}

(Received March 6, 1991)

\begin{abstract}
When Clostridium perfringens type A NCTC 8798 was grown in Duncan and Strong sporulation medium, spore formation and enterotoxin production coincided with each other, and a similar intimate relationship was observed between the sporulation and cytoplasmic inclusion body formation. The initiation of an exponential increase of the enterotoxin production was correlated with the sporulation stage III; at that time forespore formation was first seen by electron microscopy. When spore cortex become visible (stage $\mathrm{V}$ of sporulation), the inclusion body appeared. Enterotoxigenic cells and nontoxigenic mutants which differed in their sporulating abilities were examined for inclusion body formation. The results showed a close relation between sporulation, enterotoxin production, and inclusion body formation.
\end{abstract}

Clostridium perfringens is known a causative agent in human food poisoning (4). Although ingestion of various cells is usually considered to be necessary for production of this type of food poisoning, it has been established that an enterotoxin is produced by certain strains of the organism and that the enterotoxin is responsible for human diarrhea $(9,17,27)$. The enterotoxin can be detected in vitro only when cells are sporulating. However, when they are cultured in a nutritional growth medium, sporulation does not occur. This agrees with the fact that the organism is known to sporulate readily in the intestine and under such conditions would synthesize and release the biologically active toxin. Duncan et al. (5) observed that, concomitant with morphogenesis of the sporulating cell, an inclusion body was formed in the cytoplasm of the cell. The present work was attempted in

* Address reprint requests to: Dr. Kenji Takumi, Department of Food Microbiology, University of Tokushima, 3 Kuramoto-cho, Tokushima-shi, Tokushima 770, Japan. 
order to elucidate the relationships among sporulation, enterotoxin production, and inclusion body formation in C. perfringens type A NCTC 8798.

\section{MATERIALS AND METHODS}

Bacterial strains and culture conditions. C. perfringens NCTC 8798 was used throughout this study. An active culture was obtained according to the method of Duncan et al. (5). Briefly, the overnight culture of the strain in $10 \mathrm{ml}$ of fluid thioglycolate medium (BBL) was inoculated into $100 \mathrm{ml}$ of Duncan and Strong (CD) medium (7) and incubated for $3 \mathrm{~h}$. The entire culture was then inoculated into $1 l$ of DS medium and incubated at $37^{\circ} \mathrm{C}$ for the appropriate number of hours.

Assays of sporulation frequency. Light-refractile spore were examined by phase-contrast photomicrography according to the method of Labbe and Duncan (18). Cells from a growing culture of DS medium were taken at appropriate intervals and immobilized on $1 \%$ agar layers on a glass slide covered with a glass cover slip. The preparations were examined and photographed with a Zeiss phase-contrast microscope mounted with a polaroid 545 Land film holder. Percent frequency of sporulation was estimated by counting the light-refractile sporecontaining cells per total cell numbers (200-300 cells).

Purification of enterotoxin and preparation of anti-enterotoxin. Enterotoxin was purified from sonically disrupted cells from an actively growing culture of $C$. perfringens NCTC 8798 in DS medium according to the method of Sakaguchi et al. (24). The method consisted of precipitation at $40 \%$ saturation of ammonium sulfate, differential solubilization in $0.02 \mathrm{M}$ phosphate buffer, $\mathrm{pH} 6.7$, and repeated gel filtration on Sephadex G-200 (Pharmacia LKB Biotechnology AB Uppsala, Sweden). The purified enterotoxin showed a single protein band with a molecular weight of 32,000 when judged by sodium dodecyl sulfate-polyacrylamide gel electrophoresis (SDS-PAGE) as shown in Fig. 1. Mouse lethality of the toxin solution was estimated to be $400 \mathrm{MLD} / \mathrm{ml}$.

Rabbit anti-enterotoxin serum was prepared according to the previous method using Freund's complete adjuvant (30). Specific IgG from the antiserum was prepared by gel filtration on Sephadex G-200 (Pharmacia) in $0.01 \mathrm{M}$ Tris hydrochloride buffer, $\mathrm{pH} 8.0$, containing $0.02 \mathrm{M} \mathrm{NaCl}$ (32).

Reversed passive hemagglutination (RPHA). All procedures used for RPHA, including sensitization of sheep erythrocytes with anti-enterotoxin $\operatorname{IgG}$ or enterotoxin, were carried out according to the methods described by Uemura et al. (32) using a U-bottom microplate (Becton Dickinson, NJ, USA). Each sample was diluted with phosphate-buffered saline (PBS) containing $0.25 \%$ bovine serum albumin. The titer was measured after $2 \mathrm{~h}$ of incubation at room temperature, followed by overnight incubation for confirmation.

Enterotoxin detection. Aliquots $(50 \mathrm{ml})$ of actively growing culture of $C$. perfringens NCTC 8798 in DS medium were taken at appropriate intervals and centrifuged $(18,000 \times g$ for $30 \mathrm{~min})$ to remove cell pellets. The pellets were 


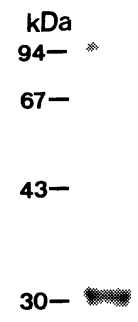

20-

$14-$

Fig. 1. SDS-PAGE profile of the purified enterotoxin of $C$. perfringens NCTC 8798. The toxin protein $(20 \mu \mathrm{g})$ was applied on the gel and eluted with molecular weight standards.

resuspended in $2 \mathrm{ml}$ PBS and sonically disrupted for $10 \mathrm{~min}$ by means of an Insonator, model $200 \mathrm{M}$ (Kubota Co., Tokyo) under cooling with ice water. The sonicated cell suspensions were centrifuged $(18,000 \times g$ for $20 \mathrm{~min})$ and the supernatant was used to assay for RPHA or an immunodiffusion test.

Immunodiffusion test. An immunodiffusion test was performed with the use of $0.8 \%$ agarose gel in $10 \mathrm{~mm}$ barbital buffer, $\mathrm{pH}$ 8.3. An antigen well contained the supernatant from sonically disrupted cells, which were taken at appropriate intervals from the growing culture in DS medium. The center well contained antienterotoxin antiserum. The results were determined after the gel was kept for 18 $\mathrm{h}$ at room temperature.

Isolation of mutants. An exponentially growing culture $(100 \mathrm{ml})$ of $C$. perfringens NCTC 8798 in GYPT medium (30) was added with $N$-methyl- $N$-nitro$N$-nitrosoguanidine (NTG, Sigma) at a concentration of $100 \mu \mathrm{g} / \mathrm{ml}$ and incubated at $37^{\circ} \mathrm{C}$ for $60 \mathrm{~min}$. Mutagenized cells were then collected by centrifugation, washed once with fresh GYPT medium, and resuspended in the same medium (10 $\mathrm{ml})$. After $6 \mathrm{~h}$ incubation at $37^{\circ} \mathrm{C}$ the cells were collected by centrifugation $(18,000$ $\times g$ for $20 \mathrm{~min}$ ) and spread on DS plates. The plates were cultured at $37^{\circ} \mathrm{C}$ anaerobically with a GasPak system (BBL). The wild-type colonies were usually opaque, whereas nonsporogenes or oligosporogenes mutant colonies were transparent (10). Based on the appearance of the colony, spore-mutant strains were isolated.

Electron microscopy. Thin sections were prepared as previously described (29). Cells were taken from the growing culture in DS medium at appropriate 
intervals, prefixed with glutaraldehyde, postfixed with sodium tetraoxide embedded in stylenemethacrylate, and cut with glass knives. Specimens were examined by a Hitachi Hu-11E electron microscope (Hitachi Co., Tokyo) at an accelerating voltage of $75 \mathrm{kV}$.

Assay of protease activity. The extracellular caseinolytic activity of sporemutants was assayed by the method of Duncan et al. (10). Culture filtrates of the mutants were prepared from $10 \mathrm{~h}$ culture in DS sporulation medium by the use of a microfilter FM-45 (pore size, $45 \mu \mathrm{m}$, Fuji Photo Film Co., Ltd., Tokyo). The filtrates were spotted on DS agar plates supplemented with $3.3 \%$ skim milk. The plates were incubated anaerobically at $37^{\circ} \mathrm{C}$ and examined for the enzyme activity after $48 \mathrm{~h}$ incubation.

SDS-PAGE. SDS-PAGE was carried out by the method described previously (30) using a separation gel of $12 \%$ acrylamide. Protein bands were visualized by staining with Coomassie brilliant blue R250. Apparent molecular weights of the proteins were calculated by comparison with standards provided by a low molecular weight protein kit (Pharmacia).

Protein assay. Protein was estimated by the method of Lowry et al. (20) using bovine serum albumin as a standard.

\section{RESULTS}

Enterotoxin production and sporulation

A time course of enterotoxin production and sporulation of $C$. perfringens

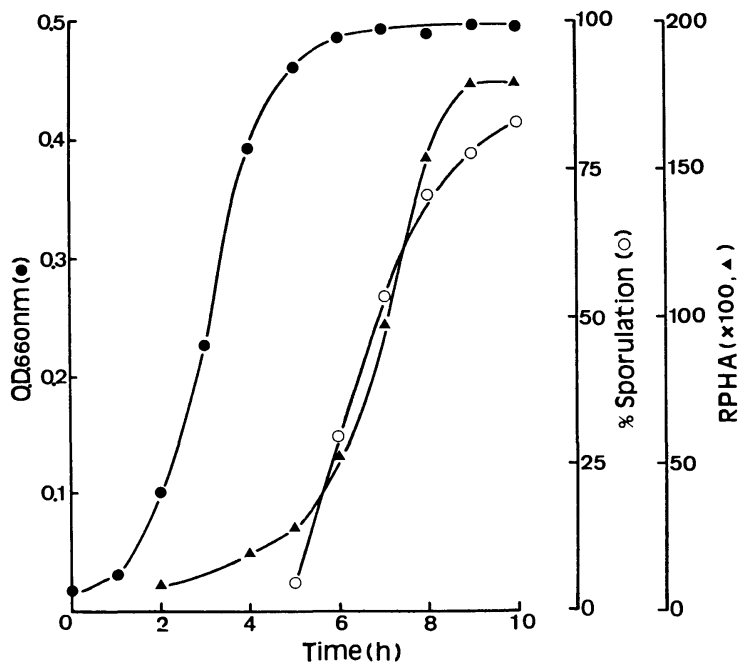

Fig. 2. The time course of enterotoxin production and sporulation of $C$. perfringens NCTC 8798 . The enterotoxin specimens were prepared from sonically disrupted cells as described in the text. Percent frequency of sporulation was determined by phase-contrast microscopy as described in the text. 


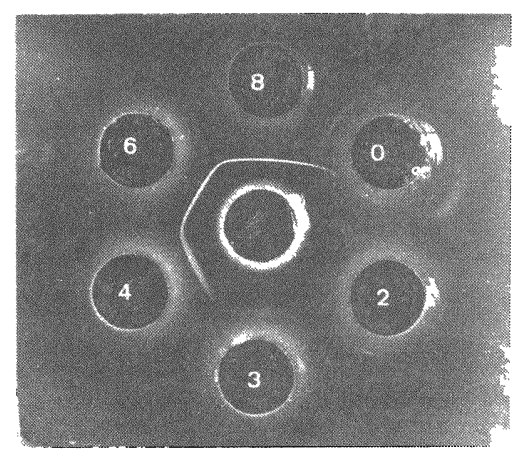

Fig. 3. Demonstration of the enterotoxin by the immunodiffusion test using a polyclonal antiserum against purified enterotoxin. The numbers on the antigen wells indicate the incubation time of the culture from which the enterotoxin was prepared.

NCTC 8798 in DS medium was illustrated in Fig. 2. At 0 time the sporulation medium contained approximately $10^{4-5}$ viable cells per $\mathrm{ml}$. Following a lag period of about $2 \mathrm{~h}$, the turbidity of the culture increased exponentially and reached a plateau at about $6 \mathrm{~h}$ incubation. Enterotoxin production was first recognized by RPHA at $2 \mathrm{~h}$ incubation. After several hours of lag period, from 2 to $5 \mathrm{~h}$ of incubation, the enterotoxin production increased exponentially and reached at a plateau within $9 \mathrm{~h}$. Such an abrupt increase in enterotoxin production was coincident with an exponential appearance of the sporungium, which reached a maximum number during approximately $10 \mathrm{~h}$ of incubation. Enterotoxin production was also detected by an immunodiffusion test (Fig. 3), by which the first, rather faint appearance of the toxin was seen at $3 \mathrm{~h}$ incubation. The extent of the immunoprecipitation reaction was gradually strengthened according to the incubation time of the cultures.

\section{Phase-contrast microscopy of spore formation}

The sequential morphological changes occurring during sporulation were surveyed by phase-contrast microscopy (Fig. 4a-f). In DS sporulation medium noticeable changes in cell shape were observed during spore formation: immediately following inoculation from a preculture medium, the cells were rather short and rod-shaped (Fig. 4a). Within $2 \mathrm{~h}$ incubation, however, the rods took an elongated pair form (Fig. 4b). By $4 \mathrm{~h}$ the cells were again beginning to form short chains (Fig. 4c), and spore-like bodies became visible after $6 \mathrm{~h}$ incubation (Fig. 4d, arrows). Within $8 \mathrm{~h}$ spores were beginning to develop refractility (Fig. 4e). Lysis of the sporangia with release of mature spores usually began at about $10 \mathrm{~h}$ incubation (Fig. 4f).

\section{Electron microscopy of spore and inclusion body}

Thin sections of the strain NCTC 8798 cells at various morphological stages of 

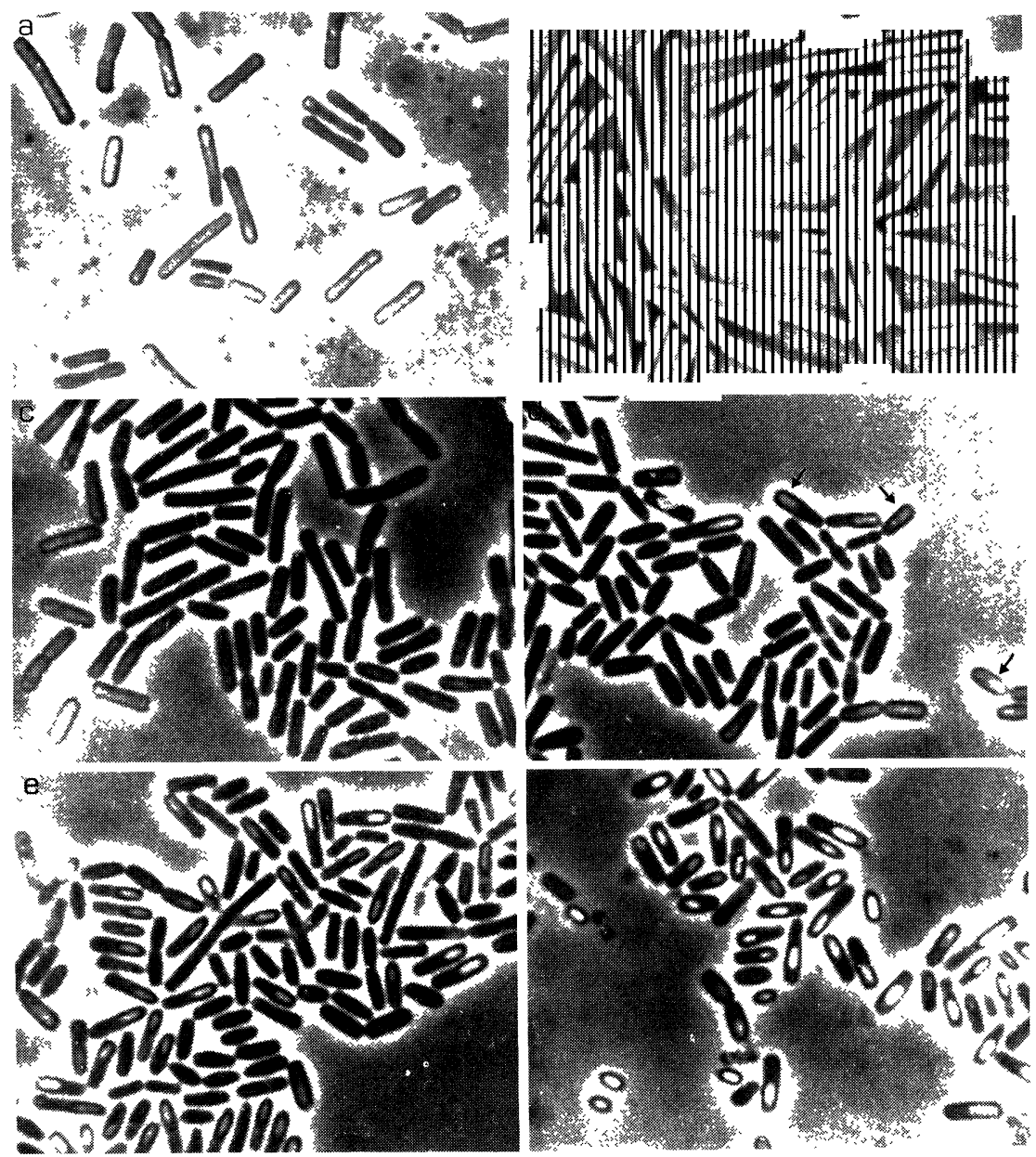

Fig. 4(a-f). Spore formation in $C$. perfringens NCTC 8798 , as observed by phase-contrast microscopy. a: $0 \mathrm{~h}, \mathrm{~b}: 2 \mathrm{~h}, \mathrm{c}: 4 \mathrm{~h}, \mathrm{~d}: 6 \mathrm{~h}, \mathrm{e}: 8 \mathrm{~h}, \mathrm{f}: 10 \mathrm{~h}$. Arrows indicate premature spores.

sporulation are shown in Fig. 5a-f. Each spore stage was determined according to the method of Hanson et al. (15). During $3 \mathrm{~h}$ incubation, spore septum formation (stage II sporulation, Fig. 5a) and forespore engulfment (stage III sporulation, Fig. 5b) were observed. At these stages no inclusion body was detected. During $4 \mathrm{~h}$ incubation the first detection of a morphologically distinct inclusion body was made concomitantly with the appearance of spore cortex (stage IV sporulation, Fig. 5c). Within $6 \mathrm{~h}$ an incubation spore coat was visible, and the inclusion body became more morphologically distinct (Fig. 5d). During $8 \mathrm{~h}$ incubation, the maturing of spores was accompanied by the appearance of a typical rectangular inclusion body (Fig. 5e and f), suggesting that the sporulation of C. perfringens NCTC 8798 
Table 1. Sporulation, enterotoxin production and inclusion body formation of wild type and mutant strains of $C$. perfringens NCTC 8798.

\begin{tabular}{llccc}
\hline $\begin{array}{c}\text { Mutant } \\
\text { strain }^{a}\end{array}$ & $\begin{array}{c}\text { Sporulation } \\
\text { class }^{b}\end{array}$ & $\begin{array}{c}\text { Enterotoxin } \\
\text { production }^{c}\end{array}$ & $\begin{array}{c}\text { Inclusion body } \\
\text { formation }^{d}\end{array}$ & $\begin{array}{c}\text { Protease } \\
\text { activity }^{2}\end{array}$ \\
\hline NCTC 8798 & Sp $^{+}$ & + & + & 20.4 \\
NTG 11 & Sp 0-1 & - & - & 6.4 \\
NTG 13 & Sp 0-1 & - & - & 2.4 \\
NTG 24 & Sp 0-1 & - & - & 6.5 \\
NTG 14 & Sp III & + & \pm & 15.8 \\
NTG I & Sp V & + & + & 18.5 \\
\hline
\end{tabular}

a Each strain was incubated at $37^{\circ} \mathrm{C}$ for $10 \mathrm{~h}$ in DS medium.

${ }^{b} \mathrm{Sp}^{+}$, Sporulation frequency of at least $80 \%$; $\mathrm{Sp} 0-1$, blocked at stage 0 or 1 of sporulation; $\mathrm{Sp}$ III and V, blocked at stage III or V of sporulation, respectively.

c Enterotoxin production was determined by a immunodiffusion test using anti-enterotoxin Rabbit serum.

${ }^{d}$ Protease activity (unit/mg of protein) was assayed by the method of Duncan et al. (10), in which the culture fluid from $10 \mathrm{~h}$ incubated in DS medium was spotted Trypticase soy agar (BBL) supplemented with skim milk. The plates were incubated anaerobically at $37^{\circ} \mathrm{C}$ for $48 \mathrm{~h}$ before determination of the enzyme activity. + : Positive, - : negative, $\pm:+$ or - .

coincides with the formation of the inclusion body.

\section{Linkage of sporulation, enterotoxin production and inclusion body formation}

For confirmation of a relationship between sporulation, inclusion body formation, and enterotoxin production, mutant strains derived from the strain NCTC 8798, which were altered in their sporulating properties, were examined for biochemical or morphological properties (Table 1). Extracellular protease is one of major biochemical markers for sporulation (21). The mutants were originally isolated by induction with NTG treatment as described in the Materials and Methods. Thin sections of the mutants for the examinations were prepared from the cells cultured at $37^{\circ} \mathrm{C}$ for $10 \mathrm{~h}$ in DS sporulation medium. For mutants NTG 11,13 , and 24 , which were nonsporulation mutants blocked at stage 0 or I of sporulation, neither enterotoxin production nor inclusion body formation were seen. Protease activity of the mutants was low in comparison with that of the parent strain. Mutant NTG 14 showed an abnormal appearance of forespore (Fig. 6a). The mutant is blocked at stage II or III of sporulation, in which enterotoxin production, but not the inclusion body, was detected. Protease activity was somewhat higher than those of the nonsporulating mutants described above. Mutant NTG I was blocked at a later stage (stage IV or V sporulation) than that of mutant NTG 14 (Fig. 6b). Either enterotoxin or inclusion body formation was clearly observed. Extent of the protease activity of the mutant was near that of the parent strain (Table 1). These results demonstrate that a direct relationship exists between enterotoxin synthesis and spore formation in C. perfringens NCTC 8798, and that the two occurrence are coincident with the appearance of the inclusion body. 

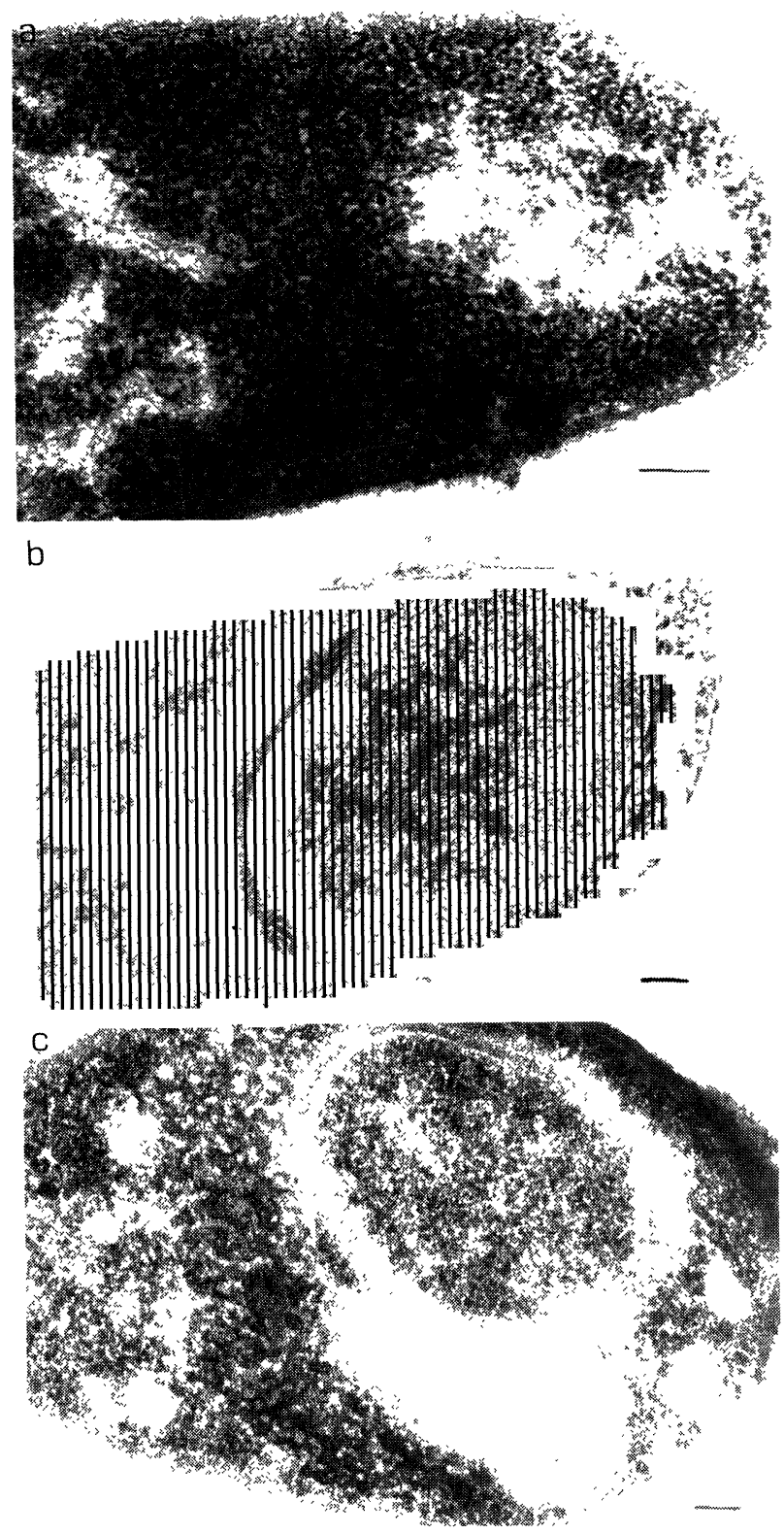

Fig. $5(\mathrm{a}-\mathrm{f})$. Electron microphotographs of thin sections of cells of $C$. perfringens NCTC 8798, at various morphological stages of sporulation. a: Spore septum formation $(2 \mathrm{~h})$, b: forespore engulfment $(3 \mathrm{~h})$, c: deposition of spore cortex $(4 \mathrm{~h}), \mathrm{d}$ : spore coat formation $(6 \mathrm{~h})$, e and $\mathrm{f}$ : mature spore $(8 \mathrm{~h})$. 


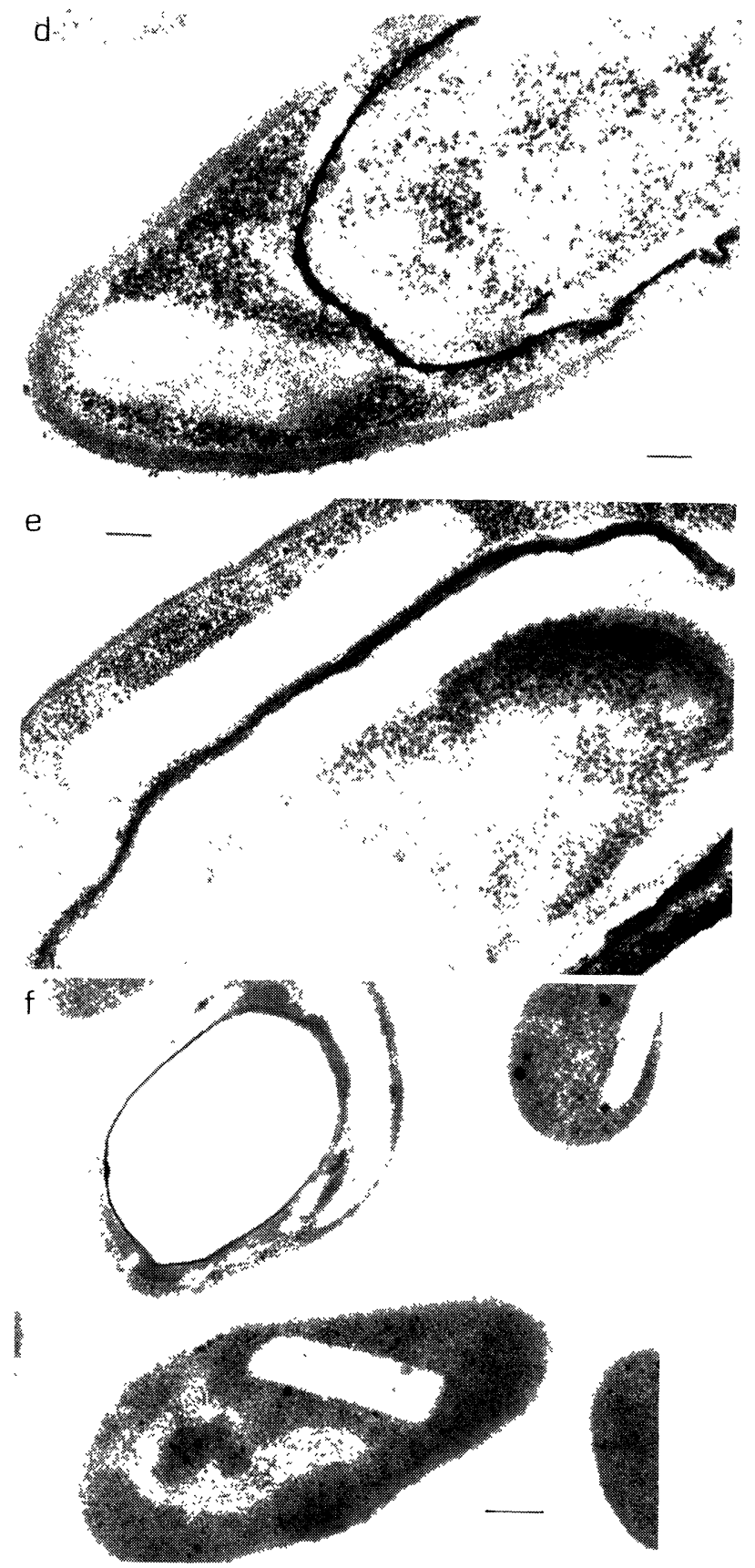




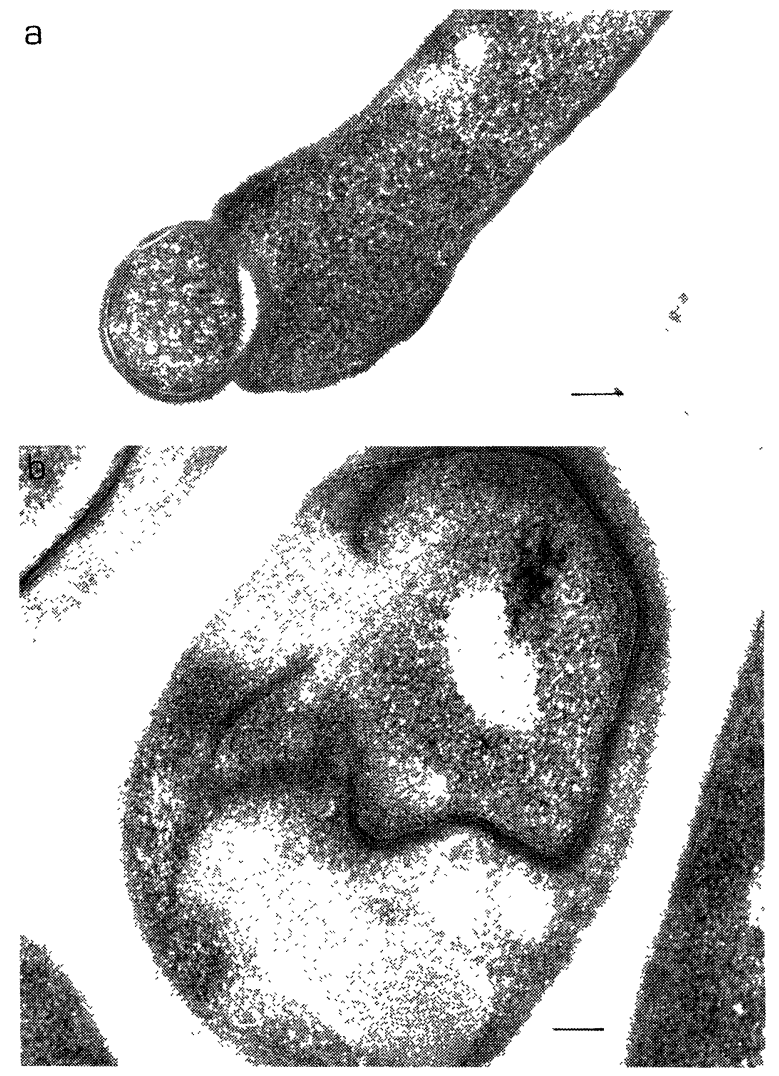

Fig. 6. Electron microphotographs of thin sections of the spore-mutants induced by NTG treatment. a: mutant NTG 14 is blocked at stage II or III of sporulation, b: mutant NTG 1 is blocked at the stage IV or V of sporulation. Note inclusion body and spore coat formation.

\section{DISCUSSION}

C. perfringens enterotoxin responsible for food-poisoning outbreaks is generally thought to be synthesized during spore formation $(10,16)$, and it has been reported that the enterotoxin protein is likely to be a sporulation-specific gene product (6). Furthermore, a paracrystalline cytoplasmic inclusion was formed only by enterotoxin-producing strains of this organism (5). These findings strongly suggested that the capacity for assembly of the morphologically distinct inclusion has an intimate relationship with sporulation similar to that of enterotoxin synthesis. The results obtained in this study presented some evidence for a close relationship between sporulation, enterotoxin production, and inclusion body formation in $C$. perfringens. The production of enterotoxin and formation of mor- 
phologically distinct inclusion were apparently related in time during spore morphogenesis. In $C$. perfringens type A, a spore coat deposition is often seen prior to the appearance of spore cortex (5), but with the strain NCTC 8798 used in this study, the appearance of cortex materials proceeded deposition of the coat layer, and at this time the initial appearance of inclusion was seen. Morphologically distinct inclusion was observed after the spore coat formation. This finding agreed well with the result obtained with mutant NTG 1, which was blocked at stage V of sporulation. Thus the formation of the inclusion body in strain NCTC 8798 is associated with a peculiar stage of sporulation.

These results, however, do not mean that the inclusion body is comprised of over-produced spore coat materials. As mentioned by Duncan et al. (5) the $C$. perfringens inclusion body appears morphologically distinct in electron micrographs from the other cytoplasmic products found in a mutant of $B$. subtilis (2) and from the inclusion of $B$. megaterium (3). The morphological distinctness of the inclusion and spore coat fragments in $C$. perfringens does not preclude the possibility that the inclusion is related to one or more spore coat structural proteins (5). Serological similarity between the enterotoxin and spore coat proteins and the autoagglutinable tendency of the enterotoxin at its isoelectric point may suggest the common identity of the enterotoxin and the inclusion and spore coat protein (5).

Although $C$. perfringens enterotoxin is produced in laboratory media that promote sporulation of the organism, there is some confusion between the sporulation and enterotoxin production $(11-13,28)$. The sporulation ability of this species is usually poor in ordinary culture media $(16,23)$, therefore, DS sporulation medium or minor modifications of it $(1,18)$ are generally used to study sporulation and enterotoxin production or both.

Since the sporulation frequency of $C$. perfringens depends on the culture medium (13), the nutritional composition of the culture medium becomes an important factor which has an influence on the enterotoxigenicity of the organism: the carbohydrate sources influence sporulation in DS medium, and raffinose in particular was effective in promoting sporulation (19). Replacement of starch with raffinose in DS medium improved the percent frequency of sporulation and increased enterotoxin concentration in the extract (19). In a chemically defined medium (22), one strain required L-methionin for sporulation, while Vitamin $\mathbf{B}_{2}$ and some amino acids were required for the other strain. Some possible end products of glucose metabolism, such as lactate, oxaloacetate, and acetaldehyde, reduced sporulation in one strain.

The sporulation or enterotoxin production of $C$. perfringens thus are dependent not only on the nutrient factors in media but also on bacterial strains. On the other hand, the failure to detect enterotoxin in cultures could be explained by the following: 1) a loss of the ability to produce enterotoxin on repeated subculture ( 8 , $14)$; 2) insufficiently sensitive assays with a high minimum level of detection, or 3 ) insufficient sample concentration $(6,12)$. Culture filtrates were concentrated 100 fold (11), and enterotoxin production is enhanced by heat treatment of the inoc- 
ulum before incubation in the sporulation medium with an increased enterotoxin yield of 256-fold for some strains $(25,31,32)$.

According to the report of Smith and McDonel (26), enterotoxin production of $C$. perfringens appears to be controlled by sporulation-specific mRNA. They examined the polypeptide synthesizing system from vegetative and sporulating cells in order to outline the elaboration of enterotoxin by toxigenic strains as well as the fundamentals of sporulation in this species. They consequently demonstrated that only the polysomes from sporulating cultures produced appreciable amounts of enterotoxin. In fact, enterotoxin comprised about $12 \%$ of the total proteinsynthesized polysomes isolated from a 6-h culture after transfer into sporulation medium.

Biochemical and genetical investigations concerning the inclusion-forming ability of a variety of enterotoxigenic and nontoxigenic strains and the mutants altered in their sporulation and enterotoxin-producing capacities must be performed.

\section{REFERENCES}

1) Adams, D. M., Inactivation of Clostridium perfringens type A spores at ultrahigh temperatures. Appl. Microbiol., 26, 282-287 (1973).

2) Balassa, G. and Yamamoto, T., Biochemical genetics of bacterial sporulation. III. Correlation between morphological and biochemical properties of sporulation mutants. Mol. Gen. Genet., 108, 1-22 (1970).

3) Beaman, T. C., Pankratz, H. S., and Gerhardt, P., Ultrastructure of exosporium and underlying inclusions in spores of Bacillus megaterium strains. J. Bacteriol., 109, 1198-1209 (1972).

4) Duncan, C. L., Clostridium perfringens food poisoning. J. Milk Food Technol., 33, 35-41 (1970).

5) Duncan, C. L., King, G. J., and Frieben, W. R., Paracrystalline inclusion during sporulation of enterotoxin-producing strains of Clostridium perfringens type A. J. Bacteriol., 114, 845-859 (1973).

6) Duncan, C. L. and Somers, E. B., Quantitation of Clostridium perfringens type A enterotoxin by electroimmunodiffusion. Appl. Microbiol., 24, 801-804 (1972).

7) Duncan, C. L. and Strong, H. D., Improved medium for sporulation of Clostridium perfringens. Appl. Microbiol., 16, 82-89 (1968).

8) Duncan, C. L. and Strong, H., Ileal loop fluid accumulation and production diarrhea in rabbit by cell-free products of Clostridium perfringens. J. Bacteriol., 100, 86-94 (1966).

9) Duncan, C. L. and Strong, D. H., Clostridium perfringens type A food poisoning. I. Response of the rabbit ileum as an indication of enteropathogenicity of strains of Clostridium perfringens in monkeys. Infect. Immun., 3, 167-170 (1971).

10) Duncan, C. L., Strong, D. H., and Sebald, M., Sporulation and enterotoxin production by mutants of Clostridium perfringens. J. Bacteriol., 110, 378-391 (1972).

11) Goldner, S. B., Solverg, M., Jones, S., and Post, L. S., Enterotoxin synthesis by nonsporulating cultures of Clostridium perfringens. Appl. Environ. Microbiol., 152, 407-412 (1986).

12) Granun, P. E., Telle, W. J., Okvik, O., and Stavin, A., Enterotoxin formation by Clostridium perfringens vegetative growth. Int. J. Food Microbiol., 1, 43-49 (1984).

13) Graven, S. E., Blankensip, L. C., and McDonel, J. L., Relationship of sporulation, enterotoxin formation and spoilage during growth of Clostridium perfringens type A in cooked chicken. Appl. Environ. Microbiol., 41, 1184-1191 (1981). 
14) Gyobu, Y., Enterotoxin production of Clostridium perfringens. J. Food Hyg. Soc. Jpn., 18, 375381 (1977).

15) Hanson, S., Peterson, J. A., and Yousten, A. A., Unique biochemical events in bacterial sporulation. Annu. Rev. Microbiol., 24, 53-90 (1970).

16) Harman, S. M. and Kautter, D. A., Improved media for sporulation and enterotoxin production by Clostridium perfringens. J. Food Prot., 49, 706-711 (1986).

17) Hauschild, A. H. W., Nilo, L., and Dorward, J., Enterotoxigenic factors of food-poisoning Clostridium perfringens type A. Can. J. Microbiol., 16, 331-338 (1970).

18) Labbe, R. G. and Duncan, C. L., Sporulation and enterotoxin production by Clostridium perfringens type A under conditions of controlled $\mathrm{pH}$ and temperature. Can. J. Microbiol., 20, 1493-1501 (1974).

19) Labbe, R. G. and Rey, D. K., Raffinose increase sporulation and enterotoxin production by Clostridium perfringens type A. Appl. Environ. Microbiol., 37, 1196-1200 (1979).

20) Lowry, O. H., Rosebrough, N. J., Farr, A. L., and Randall, R. J., Protein measurement with the Folin phenol reagent. J. Biol. Chem., 193, 265-275 (1951).

21) Mandelstam, J. and Waites, W. M., Sporulation in Bacillus subtilis. The role of exoprotease. Biochem. J., 109, 793-801 (1968).

22) Muhammed, S. I., Morrison, S. M., and Boyd, W. L., Nutritional requirements for growth and sporulation of Clostridium perfringens. J. Appl. Bacteriol., 38, 245-253 (1975).

23) Phillips, K. D., A sporulation medium for Clostridium perfringens. Lett. Appl. Microbiol., 3, 7779 (1986).

24) Sakaguchi, G., Uemura, T., and Riemann, H. P., Simplified method for purification of Clostridium perfringens type A enterotoxin. Appl. Microbiol., 26, 762-767 (1973).

25) Skielkvale, R. and Duncan, C. L., Enterotoxin formation by different toxigenic types of Clostridium perfringens. Infect. Immun., 11, 563-575 (1975).

26) Smith, W. P. and McDonel, J. L., Clostridium perfringens type A: In vitro system for sporulation and enterotoxin synthesis. J. Bacteriol., 144, 306-311 (1980).

27) Stark, R. L. and Duncan, C. L., Biological characterization of Clostridium perfringens type A enterotoxin. Infect. Immun., 4, 89-96 (1971).

28) Stelma, G. N., Jr., Misatt, K. C., Kauffman, P. E., and Sah, D. B., Radioimmunoassay for Clostridium perfringens enterotoxin and its use in screening isolates implicated in food poisoning outbreaks. J. Food Prot., 46, 1064-1073 (1984).

29) Takumi, K., Kinouchi, T., and Kawata, T., Isolation and partial characterization of exosporium from spores of highly sporogenic mutant of Clostridium botulinum type A 190 L. Microbiol. Immunol., 23, 443-454 (1979).

30) Takumi, K., Takeoka, A., and Kawata, T., Purification and immunochemical properties of a wall protein antigen from Clostridium difficile ATCC 11011. Microbiol. Immunol., 31, 837-849 (1987).

31) Uemura, T., Incidence of enterotoxigenic Clostridium perfringens in healthy humans in relation to the enhancement of enterotoxin production by heat treatment. J. Appl. Bacteriol., 44, 411-419 (1978).

32) Uemura, T., Sakaguchi, G., and Rieman, H. P., In vitro detection of Clostridium perfringens enterotoxin and its detection by reserved passive hemagglutination. Appl. Microbiol., 26, 381-385 (1973). 